\section{References}

American Psychiatric Association (1987) Diagnostic Statistical Manual III-R. Washington: APA.

British Refugee Council (1990) Asylum Seekers in the United Kingdom: Essential Statistics.

Giller, J., BRACKen, P. \& KAVAGANDA, S. (1991) Uganda: war, women and rape. Lancet, 337, 604.

Pirouet, L. (1991) Suicide and Attempted Suicide among Asylum Seekers Detained in the UK by the Immigration
Authorities. Paper presented to the Institute for the Study and Treatment of Delinquency, Canterbury.

TURNER, S. \& GORST-UnSwORTH, C. (1990) The psychological sequelae of torture: a descriptive model. British Journal of Psychiatry, 157, 475-480.

VINAR, M. (1989) Pedro or the demolition: a psychoanalytic look at torture. British Journal of Psychotherapy, 5, 353-363.

\title{
A district's view of regional in-patient units for children and adolescents
}

\author{
RoBIn BASU, Consultant Child and Adolescent Psychiatrist, Epsom Clinic, \\ Church Street, Epsom, Surrey KT17 4PP; MARY ANN GrIFFITHS, Consultant \\ Child and Adolescent Psychiatrist; and YveTte PARKer, Consultant Child and \\ Adolescent Psychiatrist, Chertsey Clinic, Stepgates, Chertsey, Surrey
}

Recommendations in the White Paper Working for Patients will have a major influence in the field of child health. District consultants have been asked by colleagues and managers to explain and account for current practice in child and adolescent psychiatry, and to plan for the future against a background of serious financial constraint. Similarly, child and adolescent psychiatrists will need to evaluate current levels of use of regional services and consider a relationship where these services may have to be bought from a limited child and adolescent psychiatry budget.

The study was aimed at examining resources presently available in the districts of South West Thames Region and current and projected use of regional services. We hope that, by clarifying what districts would need to purchase in the future, we might assist our own regional units in their development, and help ensure their future survival (Wrate \& Wolkind, 1991).

\section{The study}

Our questionnaire was sent to child and adolescent psychiatrists in the South West Thames Region, none of whom to our knowledge had in-patient beds. The questionnaire was in three parts, the first examining current provision in each district, such as hospital liaison, emergency services and access to beds; the second examining current knowledge and usage of regional services, within the region and outside it; and the third, projected use of regional services as purchasers.

\section{Findings}

Twenty-eight questionnaires were sent out and 20 replies were received ( $71 \%$ response rate). Respondents represented a cross-section of consultants within the region both in experience and in their clinical setting. 
Present clinical practice and resources within districts

The majority of child psychiatrists $(n=18 ; 90 \%)$. have their main clinical base in child guidance clinics. A substantial proportion $(n=14 ; 70 \%)$ of them also have a hospital base, although physical resources in the hospital setting vary widely, and only four could identify a room at their disposal. Five $(25 \%)$ had no hospital base.

Despite the constraints of physical resources, 15 (75\%) consultants provide a paediatric liaison service. Thirteen $(65 \%)$ offer some kind of emergency service, although formal arrangements for this were rare, while three $(15 \%)$ did not provide emergency cover. Of those districts providing an emergency service, seven $(35 \%)$ provided a casualty and overdose service, $11(55 \%)$ an out of hours on-call service and eight $(40 \%)$ an on-call rota service.

Out-patient referral rates over a five year period have shown a consistent increase in $15(75 \%)$ clinics, the increases ranging from 10 to $105 \%$. This increase has occurred despite only five $(25 \%)$ clinics offering a service to the 16 to 19 year olds age group in work, which suggests that this particular recommendation of Bridges over Troubled Waters (HAS, 1986) has not been implemented. Nineteen $(95 \%)$ of clinics provide a service to the 16-19 year age group in further education. All respondents felt they provided a service for mentally ill teenagers, children with suicidal behaviour, and severe behavioural disorders related to mental illness. The majority $(n=15 ; 75 \%)$ provide a psychotherapy service for children, and services to substance abusers, and to those who have been sexually abused, although many commented that the uptake of these services was patchy.

Only two $(10 \%)$ respondents provide a service to young people with secure needs. Specialist services such as services for communication disorders and gender identity, and the community adolescent service are based around the teaching hospital and far removed from outlying districts.

\section{Current use of regional units}

All but two (10\%) respondents have made use of regional services during the last two years, two-thirds of these being regional services within the South West Thames region. One-third of referrals were made to specialist centres outside the region. Comparing referrals from districts on to regional services with annual referral rates within districts, the regional referrals represent less than $1 \%$ of cases seen in each district. This figure represents cases where the district child psychiatrist has been involved in the referral, and does not represent referrals from other sources.

Most $(n=12 ; 60 \%)$ respondents believe that regional services offer a 9 a.m. to 5 p.m. service only, and that out-of-hours service is of a limited nature.
The majority $(n=15 ; 75 \%)$ were not clear about the operational policies of regional units and only four $(20 \%)$ felt they had sufficient information about regional services to make an informed choice. Many criticised the communication between regional units and district referrers, both at the time of admission, during assessment and at discharge.

\section{Projected use of regional services}

We found that the responses fell into two broad groups. All respondents wish, in future, to purchase assessment with a view to admission and assessment for treatment. A smaller number $(n=16 ; 80 \%)$ see emergency treatment and day places as a priority. In contrast, only $5-10 \%$ indicated a willingness to purchase family therapy, group therapy, individual therapy, or educational assessment.

Mental illness, suicidal behaviour and, psychiatric disorder associated with behavioural disorder and abuse were identified as problems requiring an urgent response. Fifteen (75\%) would like an assessment within 48 hours and admission in the same period. Eight $(\mathbf{4 0} \%)$ felt there was a need for intensive care facilities which currently are not provided at regional level.

When asked what developments in districts might be likely to influence regional referrals, $13(65 \%)$ felt day places within districts would reduce referrals and three $(15 \%)$ felt that second opinions should be available from district colleagues. Twelve (60\%) respondents felt that child psychiatrists ought to act as a filter for all referrals from districts to regional services, and recognised that child and adolescent psychiatrists are by no means the only referrers to regional units at the present time.

Eighteen ( $90 \%$ ) potential purchasers would prefer to talk to a consultant colleague when making a referral and only two (10\%) would accept consultation with another senior professional e.g. senior registrar, senior social worker.

\section{Comment}

We were dismayed to find that, contrary to College guidelines (Royal College of Psychiatrists, 1987), a sizeable proportion of child and adolescent psychiatrists did not have a hospital base and operated solely from child guidance clinics. Most were involved in some aspect of hospital services, but lacked basic resources, such as a room, a telephone, a secretary, or direct access to beds. This undoubtedly contributes to the lack of organisation of emergency services. While there was some district variation, by and large child psychiatrists were not involved in managing emergencies after 5.00 p.m. and were dependent on both registrars and consultants in the adult psychiatry department to do this. 
The workload of child and adolescent psychiatrists has increased dramatically during the last five years, although the recommendations of the Health Advisory Service (Bridges over Troubled Waters, 1986) have not been implemented and child psychiatrists deal only with those 16 to 19 year olds who remain in education. Thus, selective practice, increasing workload, and inadequate manpower, together with limited physical resources, mean that hospital-based services and emergency provision cannot be properly developed.

All child and adolescent psychiatrists made use of regional services but total referrals accounted for less than $1 \%$ of child and adolescent caseload. Selection of units may well be accounted for by geography and discreet knowledge of services, especially services provided by individual units, e.g. for sexually abused patients. The above factors may account for the surprisingly large number of referrals to units outside the region. With the changes in the funding of regional services and the probability that districts will need to purchase direct, there may be conflict between supporting the local provider unit and retaining a choice for the purchaser.

Future purchasers of regional services identified emergency services as a priority. This is not surprising considering the lack of emergency provision and beds within districts. A sizeable proportion of consultants felt they were not aware of the operational policies of the regional services and wished greater involvement in the process of admission, assessment and discharge with improved communication on formulation, differential diagnosis and prognosis of the cases. Clearly there was a preference for increased informal and formal consultation. Most future purchasers endorsed the idea of child and adolescent psychiatrists from districts acting as filters for all referrals from within a district as a means of ensuring greater budgetary control. Many consultants felt that regional services could be less insular and more userfriendly and welcomed the idea of specialists from these units having better liaison with their district colleagues in training and consultation. As the service moves into a new phase in the light of the White Paper recommendations district child and adolescent psychiatrists will have to give increasing consideration to administration and budgetary policies.

Responses to our questionnaire indicated that child and adolescent psychiatrists were not fully aware of their role as future budget-holders and purchasers of regional services. Clearly there is an overwhelming endorsement of the need for regional services as providers of inpatient assessment and treatment which cannot be duplicated at district level.

\section{References}

Health Advisory Service (1986) Bridges Over Troubled Waters. Report from NHS on Services for Disturbed Adolescents. London: HMSO.

WRATE, R. M. \& WolkIND, S. (1991) Child and adolescent psychiatry in-patient units. Psychiatric Bulletin, 15, 37-38.

Royal College of Psychiatrists (1987) Child and Adolescent Psychiatrists Specialist Section: Notes for the Guidance of College Regional Advisers concerning post in Child and Adolescent Psychiatry. Bulletin of the Royal College of Psychiatrists, 11, 142-143. 